\title{
Characteristics of the Yamase Winds over Oceans around Japan Observed by the Scatterometer-Derived Ocean Surface Vector Winds
}

\author{
Hiroshi TAKAI \\ Japan Weather Association, Tokyo, Japan \\ Hiroshi KAWAMURA and Osamu ISOGUCHI \\ Center for Atmospheric and Oceanic Studies Graduate School of Science, Tohoku University, Sendai, Japan \\ (Manuscript received 18 March 2004, in final form 22 December 2005)
}

\begin{abstract}
Yamase is the name for local northeasterly winds that blow from the Pacific Ocean to the east coasts of Hokkaido, and the Tohoku District from May to August. They are cool and moist winds accompanied by low-level clouds. In the present study, we investigate the Yamase winds over the oceans around Japan, using ocean surface vector winds observed by a satellite-scatterometer. In order to define the Yamase Phenomena, we employed an Empirical Orthogonal Function (EOF) analysis of the AMeDAS surface air temperatures over the Tohoku District from May to August. Daily mean temperature anomaly $(\Delta T)$, which is a deviation from the climatological daily mean temperature, is calculated for the 167 AMeDAS stations. The spatial coefficient function of the EOF first mode (EOF1), shows synchronous temperature changes in the whole Tohoku District, while that of the EOF second mode (EOF2), shows a seesaw pattern of temperature variation, between the Pacific and Japan Sea sides. The EOF-decomposed temperature variation, and $\Delta T$ at the Hachinohe station (a Yamase index), has high correlations; for EOF1, the correlation is 0.78 , and for EOF1+2, it becomes 0.89. The Yamase Phenomena represented by the Hachinohe negative $\Delta T$, is thus associated with two different patterns of the temperature variations in the Tohoku District.

The composite wind map made through the sampling of days, with the Hachinohe $\Delta T<-2^{\circ} \mathrm{C}$, shows northeasterly ocean winds blowing toward the Sanriku coast, an anti-cyclonic circulation center in the eastern Okhotsk Sea, and northeasterly surface winds along the Kuril Islands. When the winds approach the Tohoku District in the Pacific Ocean, they separate two flows around $40^{\circ} \mathrm{N}$ off Miyako. The surface wind fields associated with the cold phenomena of EOF1 and EOF2 corresponding to the Hachinohe negative $\Delta T$ are different. The former indicates the northeasterly wind blowing toward the Sanriku coast, and the latter that the northeasterly winds from the sea south of the Kuril Islands, change their direction around $145^{\circ} \mathrm{E}$ and the easterly winds blow toward the Sanriku coast. The Kitakami Mountains influence significantly on the Yamase winds, over the coastal Pacific Ocean.
\end{abstract}

\section{Introduction}

Northeasterly to easterly surface winds often blow from the Pacific Ocean toward the Tohoku

Corresponding author: Hiroshi Kawamura, Center for Atmospheric and Oceanic Studies, Graduate School of Science, Tohoku University, Sendai, Miyagi, 980-8578 Japan.

E-mail: kamu@ocean.caos.tohoku.ac.jp

(C) 2006, Meteorological Society of Japan
District and Hokkaido from May to August. The winds have been called "Yamase" and are classified as local winds (Heibonsha 1986). Its air is cool, wet and usually associated with low-level clouds and fog, which reduce incident surface solar radiation. The Yamase winds sometimes blow continuously for a long time, which yields a cold summer with serious damage of rice crops (e.g., Kondo 1988). 
Using meteorological observation data over the land, the Yamase Phenomena have been studied for a long time. Yamase days, when the Yamase winds are dominant, were defined with several surface meteorological parameters (for example, Kon 1984; Kanno 1993; Takai and Kawamura 2002). They used the observation data of the meteorological stations at the $\mathrm{Pa}$ cific coast in the Tohoku District, because they captured typical Yamase related parameters, i.e., air temperature (low) and surface wind (easterly-northeasterly wind).

In order to investigate its wider influences, Ninomiya and Mizuno (1985a) conducted EOF analyses of the monthly/daily mean temperature anomalies at many meteorological stations in Japan, and found that the strong northeasterly wind affects the whole of Japan beyond the Tohoku District. Fujibe (1995) performed principal component analyses, by using various observation data (monthly mean temperature, pressure, sunshine duration etc.), and found the similar features as found by Ninomiya and Mizuno (1985a).

It is well known that the Yamase winds are associated with the high-pressure system over the Okhotsk Sea. Using the marine meteorological data, Ninomiya and Mizuno (1985b) concluded that the Yamase winds are advection of the maritime air mass from the Okhotsk Sea, the Bering Sea and the northern North Pacific. Takai et al. (1996), and Kodama (1997) showed that the advection features of the Yamase's airmass from the northern oceans by back trajectory analyses, using the objective analysis data.

Kawamura (1995) has demonstrated that the new satellite remote sensing methods capture well the features of Yamase winds in a wider area (Yamase Phenomena), as well as the traditional visible and infrared radiometers onboard the operational meteorological satellites. The satellite scatterometer was considered to be a powerful tool to fill large observational gaps of the surface winds in the open ocean (e.g., Freilich 1985; Kawamura 2003). Since the Yamase is the surface wind blowing from the northern oceans, the scatterometer enables us to investigate its detailed features over the vast sea area (Kawamura 1995). In addition to that, recent studies have revealed that it is also useful to observe interactions between the ocean surface winds and the lands (e.g., Kawa- mura and Wu 1998; Luis and Kawamura 2000, 2002).

In this study, we investigate characteristics of the sea surface wind field associated with the Yamase Phenomena around Japan. Section 2 describes observation data used in the present study, and Section 3 presents the results; we employed EOF analysis of the surface air temperature records to define the Yamase Phenomena and investigate the scatterometer wind fields associated with them. Discussions and conclusions are given in Sections 4 and 5, respectively.

\section{Data and methods}

The ocean surface vector winds observed by the microwave scatterometer, SeaWinds, are used in the present study. The NASA/QuikSCAT satellite carrying the SeaWinds was lofted into space on 19 June 1999 by NASA. The satellite sensor uses a rotating dish antenna, with two spot beams that sweep in a circular pattern. The antenna emits microwave pulses of $13.4 \mathrm{GHz}$ toward the Earth's surface, and receives the backscattered signals. Its observational swath is $1,800 \mathrm{~km}$ along the satellite track, and the spatial resolution of retrieved ocean surface vector winds has a highest spatial resolution of about $25 \mathrm{~km}$. The SeaWinds Level 3 Data Set contains daily $0.25^{\circ} \times 0.25^{\circ}$ vector winds in the global oceans. It covers $90 \%$ of the Earth's surface in one day, making approximately 400,000 measurements. Accuracy of the wind-speed measurements is about $2 \mathrm{~m} / \mathrm{s}$ for the range of 3 to $20 \mathrm{~m} / \mathrm{s}$, and the accuracy of wind direction is about 20 degrees (http://winds.jpl.nasa.gov/missions/ quikscat/index.cfm). We use QuikSCAT daily mean wind fields on $0.5^{\circ} \times 0.5^{\circ}$ for the area of $30^{\circ}-65^{\circ} \mathrm{N}$, and $130^{\circ}-180^{\circ} \mathrm{E}$ (the study area is shown in Fig. 1) from May to August in 20002002 (total 369 days), which were obtained from the Mean Wind Fields (MWF) products (IFREMER/CERSAT, 2002).

AMeDAS (Automated Meteorological Data Acquisition System) is an observation system of land-surface meteorological parameters operated by the Japan Meteorological Agency. Approximately 1,300 stations are distributed all over Japan, with intervals of about $17 \mathrm{~km}$. In the present study, we used hourly air temperature, wind direction, and speed observed at the 


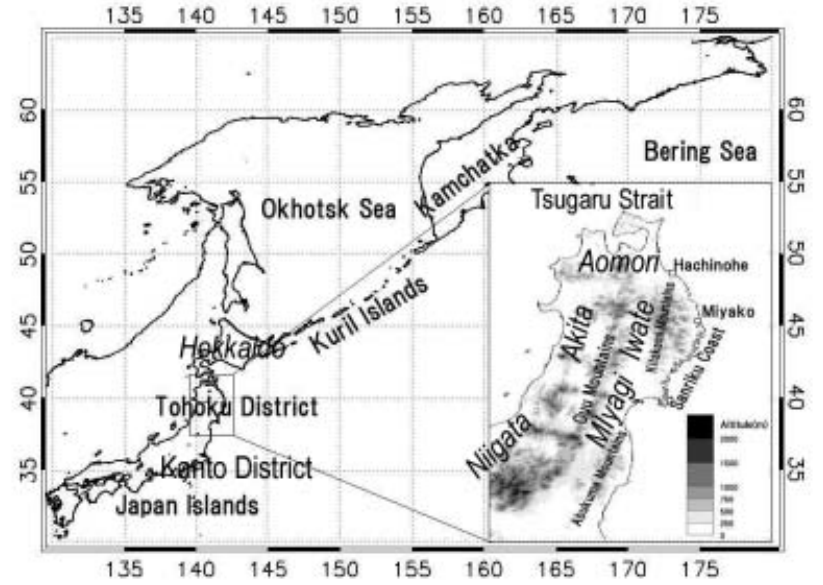

Fig. 1. Study area. The scatterometer surface vector winds are analyzed in the area of $30^{\circ}-65^{\circ} \mathrm{N}$ and $130^{\circ}-180^{\circ} \mathrm{E}$. Topography of the Tohoku District is also shown.
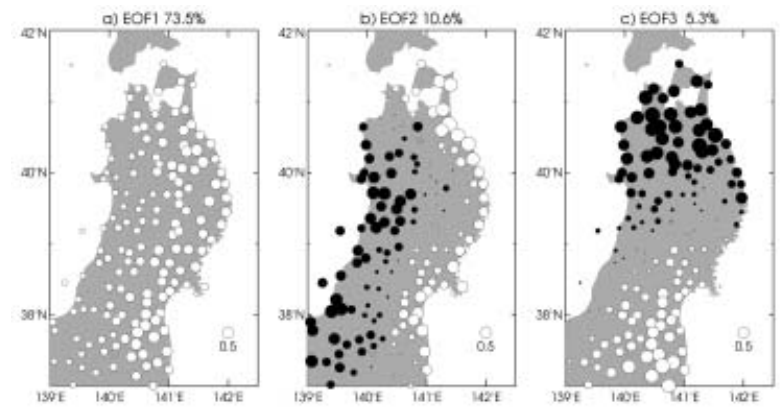

Fig. 2. Spatial coefficient functions of EOF modes at each AMeDAS station. a) $\operatorname{EOF} 1(x, y)$ map, b) $\operatorname{EOF} 2(x, y)$ map and c) $\operatorname{EOF} 3(x, y)$ map. The eigenvalues of EOF1, EOF2 and EOF3 at the Hachinohe station are $0.45,0.63$ and -0.67 , respectively.

167 AMeDAS stations in the Tohoku District and the eastern part of Niigata Prefecture (See Fig. 2). Hereinafter the area including the eastern part of Niigata Prefecture is referred to as the Tohoku Distinct in this study. The AMeDAS stations along the Pacific coast of the Tohoku District are located with intervals of about $20 \mathrm{~km}$. Land topography of the Tohoku District is illustrated in Fig. 1.

We calculated daily mean temperature anomaly $(\Delta T)$, for the $167 \mathrm{AMeDAS}$ stations from May to August in 2000-2002. It is a devi- ation from the climatological daily mean temperature, which is calculated for every calendar day at each station, using the observations of 1971-2000. The air temperature at the Hachinohe station was often used as an index of Yamase days (e.g., Kanno 1993). When the Yamase winds blow, the air temperature at the Hachinohe station becomes low.

To analyze $\Delta T$ variations in the study area, we employ the EOF (Empirical Orthogonal Function) analyses. In general, the daily temperature time series at a fixed point $T(x, y, t)$, is expanded as follows.

$$
\begin{aligned}
T(x, y, t) & =\sum_{i=1}^{n} \operatorname{Ti}(x, y, t) \\
& =\sum_{i=1}^{n}(\operatorname{EOFi}(x, y) \times \operatorname{TC} i(t)),
\end{aligned}
$$

where EOF $i$ is the spatial coefficient function, $\mathrm{TC} i$ the time coefficient series, and $i$, denotes the EOF mode number (e.g., Ninomiya and Mizuno 1985a).

\section{Results}

To examine characteristics of the temperature variations in the study area, EOF analyses were performed by using time series of $\Delta T$, obtained from the 167 AMeDAS stations. We first calculated the covariance matrix of $\Delta T$, for the following EOF expansion. Figure 2 shows, at each station, the spatial coefficient function of first, second, and third modes, which are EOF1, EOF2 and EOF3, respectively. Figure 3 shows TC $i$ of the first three modes. The contribution ratios of the first three EOF modes are $73.6 \%$, $10.6 \%$, and $5.3 \%$, respectively.

EOF1 at each station shown in Fig. 2 has the same sign, which means that temperature changes of this mode, have common variation tendencies in the whole study area. In contrast, the EOF2 signs are positive (negative) at the stations in the Pacific side, and negative (positive) at the stations in the Japan Sea side. In the Pacific side, the amplitudes (the size of circle) are larger for the stations at the coastal area, and low-altitude flat lands of Aomori and Miyagi Prefectures. The inland stations west of the Kitakami Mountains in Iwate Prefecture have smaller amplitudes, and the same sign of EOF2, as those in the Japan Sea side. It can be considered that the EOF2 mode is influ- 


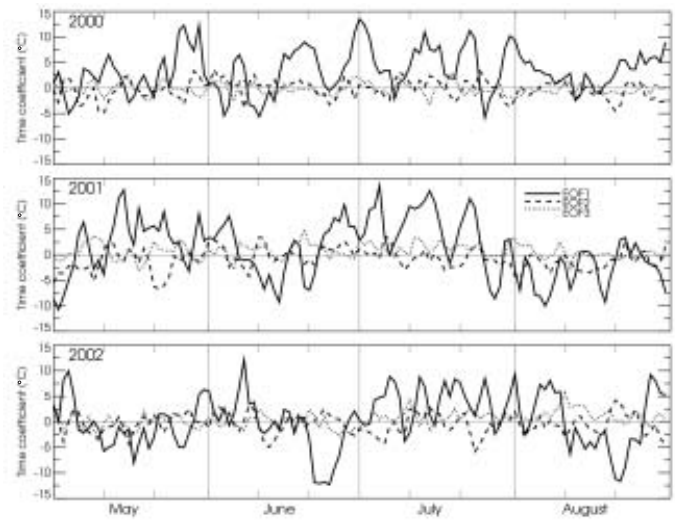

Fig. 3. Time coefficient series of EOF modes and time series of the Hachinohe $\Delta T$ for May to August of 2000-2002. The vertical axis has temperature dimension of ${ }^{\circ} \mathrm{C}$. The time series of EOF first, second and third modes are shown by solid, dashed and dotted lines, respectively.

enced by the topographic features in the Tohoku District, because the lines dividing the phase of EOF2, coincides with the major mountain chains, i.e., the Kitakami, the Ouu and the Abukuma Mountains (Fig. 1). The signs of EOF3 are negative/positive in northern/southern Tohoku District.

In order to compare the temperature variations of EOF modes, and $\Delta T$ at the Hachinohe station, we calculated $T i(t)$ by multiplying $\operatorname{EOF} i(t)$ and $\mathrm{TC} i(t)$ at the Hachinohe station. Since the $T i(t)$ and $\Delta T(t)$ have the same unit of temperature (degree Celsius), the comparison is meaningful.

Correlation coefficients between the time series of the Hachinohe $\Delta T(t)$, and the $T 1(t)$, $T 2(t)$ and $T 3(t)$ are $0.78,0.42$ and -0.32 , respectively. The correlation between temporal variations of the Hachinohe $\Delta T$, and $T 1$ is very high, and that for $T 2$ is also significantly high. Figure 4 indicates $\Delta T(t), T 1(t)$ and $T 1(t)+T 2(t)$ for May-August of 2000-2002. During May-August of 2000-2002 (total 369 days), the number of days with $\Delta T<2^{\circ} \mathrm{C}$ is 90 , while the number of day with $T 1<0$ is 135 . When we compare the Hachinohe $\Delta T(t)$ and the sum of $T 1(t)$ and $T 2(t)$, the correlation coefficient becomes 0.89 . Though in the previous studies negative anomaly appearance of the air

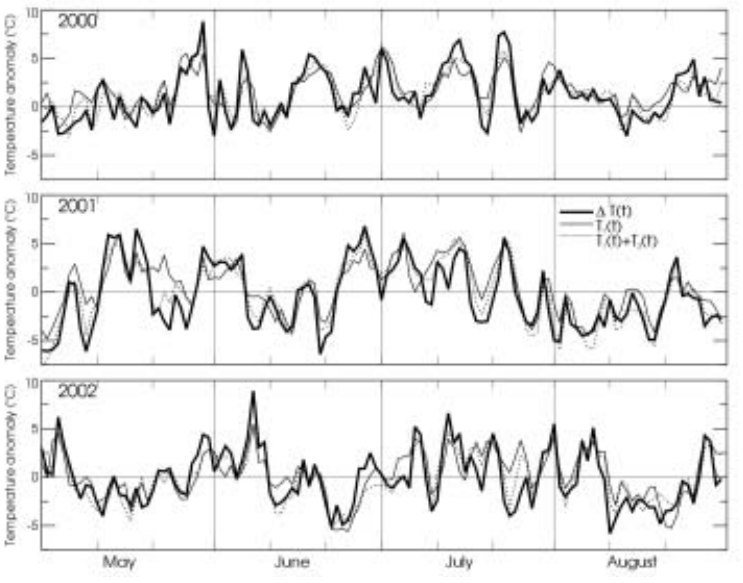

Fig. 4. Time series of the $\Delta T$ (thick solid line), $T 1(t)=\mathrm{EOF} 1 \times \mathrm{TC} 1(t)$ (thin solid line) and $T 1(t)+T 2(t)$ (dotted line) at the Hachinohe station. The correlation coefficients between $\Delta T$ and $T 1$ and $\Delta T$ and $T 1+T 2$ are 0.78 and 0.89 , respectively.

temperature at the Hachinone station was often used as the index of Yamase days (e.g., Kon 1984; Kanno 1993; Takai and Kawamura 2002), it is shown that the Hachinohe $\Delta T$, is associated with two distinctly different spatial patterns of $\mathrm{EOF}$ modes, i.e., $\operatorname{EOF} 1(x, y)$ and $\operatorname{EOF} 2(x, y)$.

In Fig. 5, snapshot fields of the ocean surface vector winds, observed by the SeaWinds, are illustrated for days with negative Hachinohe $\Delta T$. Figure 5a shows the vector-wind distribution on 1 August 2001, when the daily mean temperature at Hachinohe $\left(17.5^{\circ} \mathrm{C}\right)$ was $5.0^{\circ} \mathrm{C}$ lower than the climatological daily mean. At the station, the wind direction was ENE, and the sunshine duration was 0 hour. The lower temperature anomaly was also recorded in the next day $\left(5.1^{\circ} \mathrm{C}\right)$. Figure $5 \mathrm{~b}$ illustrates the surface vector wind distribution on 6 August 2001, when the daily mean temperature at Hachinohe was $18.0^{\circ} \mathrm{C}\left(-4.5^{\circ} \mathrm{C}\right.$ in anomaly). The wind direction was ESE. The daily mean temperatures at Hachinohe for 4-10 August 2001, had about $2{ }^{\circ} \mathrm{C}$ lower anomalies, and the wind directions were easterly. As mentioned above, the scatterometer vector-wind distributions capture the Yamase Phenomena in the wider ocean areas of the northwestern North Pacific, and the Okhotsk and Bering Seas. 

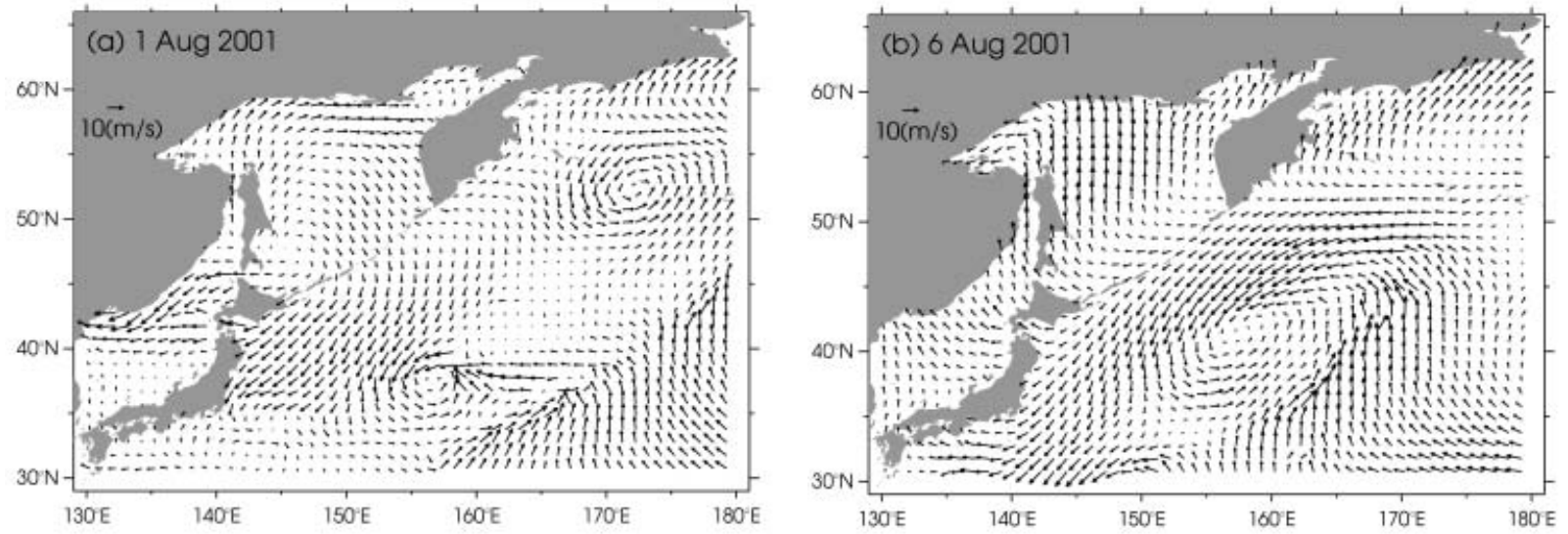

Fig. 5. The surface-vector wind distributions obtained by the QuikSCAT/SeaWinds in the northwestern North Pacific and the Okhotsk and Bering Seas. a) On 1 August 2001 and b) on 6 August 2001.

Through conditional sampling of days with the Hachinohe $\Delta T<-2^{\circ} \mathrm{C}$ (90 days), we made a composite map of the surface vector wind (Fig. 6). In general, the applied conditions sampled strong Yamase days (Kanno 1993; Takai and Kawamura 2002). The composite map shows that the northeasterly ocean winds blow toward the Sanriku coast (See Fig. 1). There is a core of anti-cyclone in the eastern part of the Okhotsk Sea, and the northeasterly surface winds blow along the Kuril Islands. When these winds approach Hokkaido, and Tohoku District in the Pacific Ocean, they separate two flows around $40^{\circ} \mathrm{N}$ (off Miyako, see Fig. 1). It is

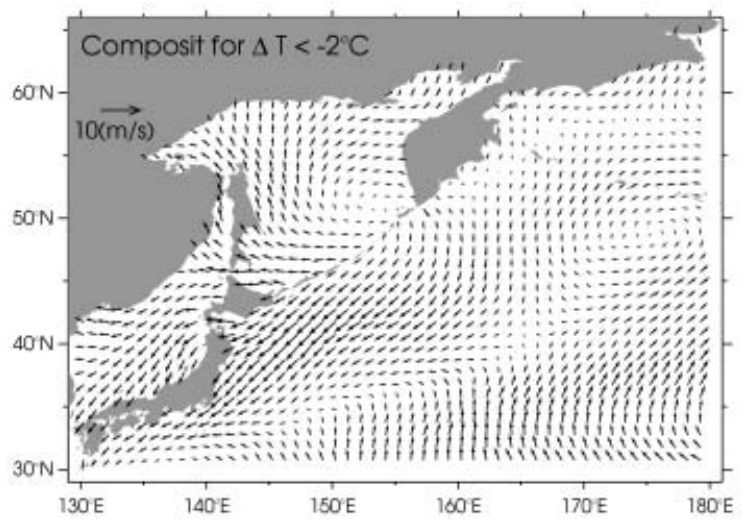

Fig. 6. Composite map of the ocean surface vector wind fields with the sampling condition of the Hachinohe $\Delta T<$ $-2^{\circ} \mathrm{C}$. seen that the surface air flow, which is separated toward the north, passes through the Tsugaru Strait, being intensified. On the other hand, another separated wind blows toward the Kanto District.

Using the time coefficients of three EOFs shown in Fig. 3, we made the sea surface wind composite maps. In order to make the composite map of EOF1 cold phenomena (Case-1 hereafter), we sampled the surface wind fields when the $\operatorname{TC} 1(t)$ time series value is lower than -0.5 standard deviation $(\sigma)$ (72 days). They are averaged to make a composite map of sea surface wind field (Fig. 7a). Figure 7a shows a similar wind field to Fig. 6, although they were created based on different criteria. Following the above-mention procedure, we produced composite maps for the EOF2 (149 days for TC2 $(t)<-0.5 \sigma$ ) and EOF3 (140 days for $\operatorname{TC} 3(t)>0.5 \sigma)$ corresponding to a negative temperature anomaly in the Pacific side (Fig. $7 \mathrm{~b}$, Case-2), and a negative temperature anomaly in the northern Tohoku District (Fig. 3, Case-3). These are associated with the negative temperature anomalies, at the Hachinohe station as well.

As seen in Fig. 7a (Case-1), the northeasterly wind blows toward the Sanriku coast. Convergence zone from $\left(30^{\circ} \mathrm{N}, 130^{\circ} \mathrm{E}\right)$ to $\left(40^{\circ} \mathrm{N}, 160^{\circ} \mathrm{E}\right)$ is seen, which can be considered to be associated with the Baiu front, because it is a longpersisting typical weather pattern in this season. The surface air from the seas around the 

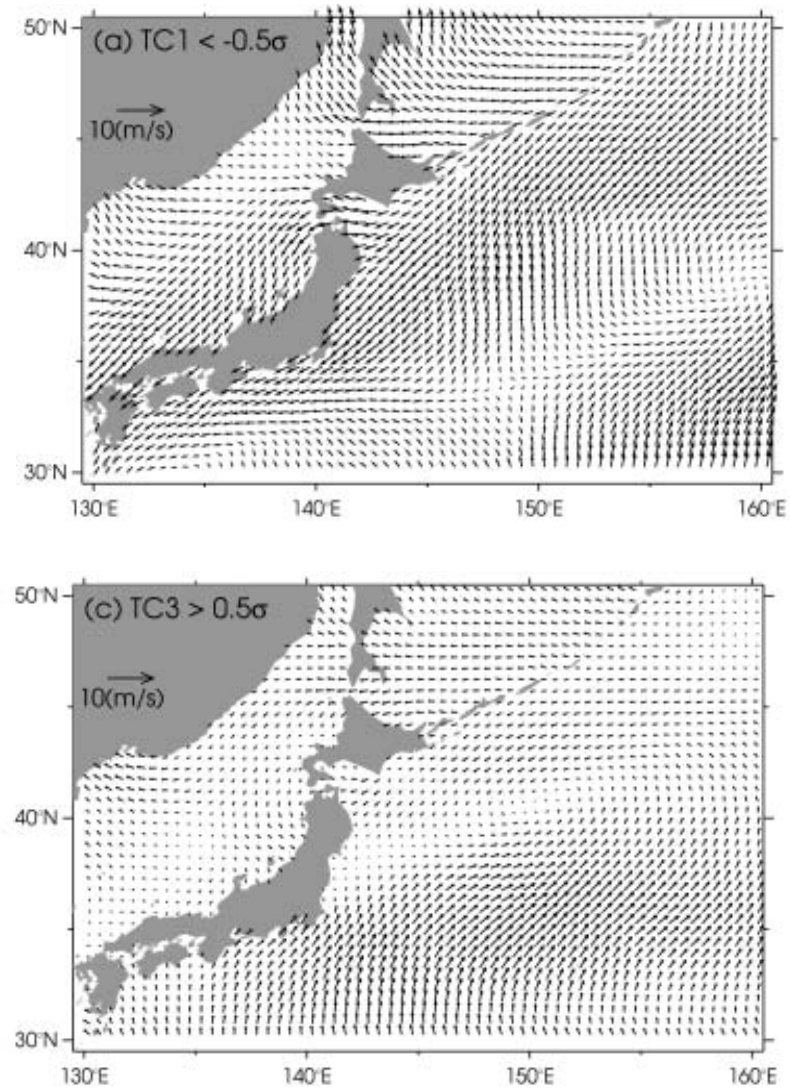

Kuril Islands streams both coasts, the Pacific Ocean and the Japan Sea of the Tohoku District. This may be the reason that the whole area of the Tohoku District has large negative anomalies for Case-1.

The flow pattern of Case-2 is different from that of Case-1; the northeasterly winds from the sea south of the Kuril Islands change their direction around $145^{\circ} \mathrm{E}$, and the easterly winds blow toward the Sanriku coast. In this case, the wind speed is not high in the Japan Sea, but becomes high in the Pacific south of Hokkaido and in the Tsugaru Straits. In the sea off the Kanto District, the wind direction changes to the south. It is shown in Fig. 2b that Case-2 has the high contrast of temperature anomaly in the east side (low) and the west side (high) of the Tohoku District.

Case-3 corresponds to the negative/positive anomalies in the northern/southern Tohoku District (Fig. 2c). The composite wind field illustrated in Fig. 7c shows that weak easterly winds appear only in the coastal sea off the

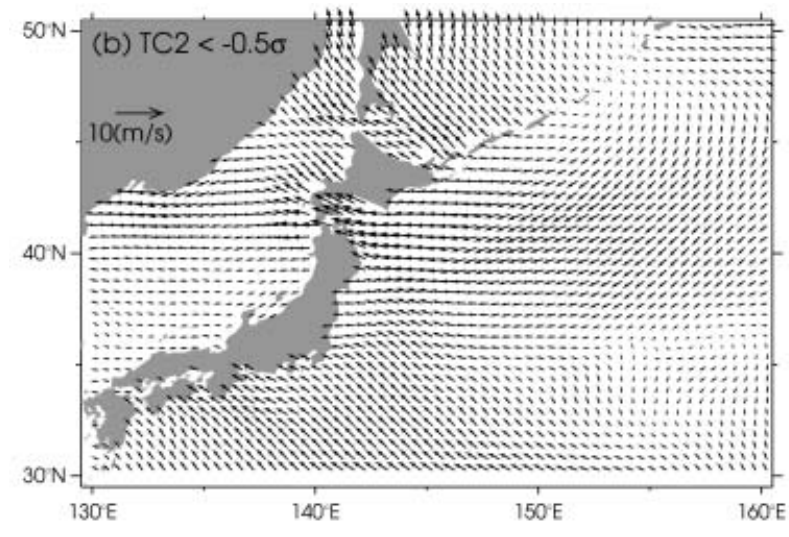

Fig. 7. Composite maps of the sea surface wind fields corresponding to TC1 negative, TC2 negative and TC3 positive in Fig. 3, which are related to the cold phenomena in the Tohoku District (See the text). a) Composite map for TC $1<-0.5 \sigma$, b) composite map for TC2 $<-0.56 \sigma$ and c) composite map for TC3 $>0.56 \sigma$.

northern Tohoku District, which may be the reason for the negative temperature anomaly there. The southerly wind blows into the Kanto District, which may be associated with its positive temperature anomaly.

We produced the composite maps for EOF cases in which the TCis have different signs from Case-1, 2 and 3, i.e., $\mathrm{TC} 1(t)>0.5 \sigma$, $\mathrm{TC} 2(t)>0.5 \sigma$ and $\mathrm{TC} 3(t)<-0.5 \sigma$. In contrast to the composite maps in Fig. 7, these maps show southerly winds blow into Japan from the southern seas (No figures are shown).

\section{Discussions}

Using meteorological observation data over the land, the Yamase Phenomena have been studied for a long time. In contrast, there is quite little information on the Yamase related surface variables in the oceans. In general, the surface pressure field is one of the marine parameters used for monitoring the Yamase related phenomena over the ocean. In the present study, the Yamase Phenomena are investigated 
in the oceans around Japan, by using the surface vector winds observed by the satellite scatterometer. It provides the vector winds with high temporal/spatial resolution for wider areas of the ocean.

The Yamase winds are usually trapped in the atmospheric boundary layer, and they advect the cold and moist air mass associated with the low-level clouds (Ninomiya and Mizuno 1985b; Kanno 1997; Kodama 1997; Takai et al. 1996). The top of low-level clouds has a typical height of about 1-2 kilometers (e.g., Takai and Kawamura 2002). It is clearly indicated by the scatterometer winds that the surface vector wind fields are influenced by the land topography; they are bifurcated off Miyako at the Sanriku coast, which may be influenced by the Kitakami Mountains.

It is indicated that the EOF2 mode is influenced by the topographic features in the Tohoku District, because the lines dividing the phase of EOF2 (Fig. 2b) coincides with the major mountain chains, the Kitakami, the Ouu, and the Abukuma Mountains (Fig. 1). In Case2 of cold phenomena, the surface winds approach the Tohoku mountain chains from the east, and hit them with almost perpendicular angles (Fig. 7b). Using the NOAA visible images, Takai and Kawamura (2002) investigated the cloud distributions associated with the Yamase condition, and showed that the east sides of the mountain chains are covered by the low-level Yamase clouds and the west sides are cloud free (Fig. 7 in Takai and Kawamura 2002). In this case, the Yamase clouds advected from the Pacific Ocean are considered to be blocked by the mountain chains. Because of the high cloud albedo, the solar radiation does not reach the east-side land. In contrast, the west side experiences significant diurnal heating, due to the insolation. An appearance mechanism of the EOF2 pattern may be explained by the topographic effect on the Yamase cloud distribution.

Kawamura (1977) analyzed typical landsurface wind fields over Japan. One of them is considered to correspond to the Yamase Phenomena (Type-G of Kawamura 1977); when the wind derived from the surface pressure map has wind directions of $70^{\circ}-120^{\circ}$ around the Tohoku District, the surface air flow pattern has unique features influenced by the land topography. The Yamase winds blow from the Pacific Ocean into the Tohoku District, and flow out to the Japan Sea. The scatterometer winds have shown the typical flow pattern of Yamase Phenomena in the oceans around Japan. The Yamase winds with high speeds pass through the Tsugaru Strait. Channeling effects may enhance their intensity there. The topographic effects on the Yamase winds need to be investigated in future studies.

In order to clarify the cooling mechanisms of the Tohoku District, more quantitative analysis, introducing new parameters such as sea surface temperature and air temperatures are necessary. However, it is beyond the scope of the present study, and also left for future studies.

Finally, we discuss the results of EOF analysis by Ninomiya and Mizuno (1985a) in comparison with the present results. Their spatial coefficient maps of the first and the second modes (e.g., their Fig. 5) are similar to our EOF1+EOF2 and EOF3. They used monthly mean surface temperature of 51 stations distributed over the whole of Japan. The analyzed period is 1951-1980. In contrast, our data are daily mean surface temperature of $167 \mathrm{AMe}-$ DAS stations in the Tohoku District for 20002002. Our temporal/spatial resolutions of surface temperature measurements are much higher than those of Ninomiya and Mizuno (1985a), and the analyzed regions are different, which may result in the differences between the patterns of EOF spatial coefficient.

\section{Conclusions}

Using the ocean surface vector winds derived from the satellite scatterometer and landsurface meteorological parameters measured at the AMeDAS stations, we investigated the Yamase Phenomena over the wide area of oceans around Japan. The following conclusions are obtained.

1) EOF analysis of the land air-temperature anomaly from May to August in the Tohoku District showed that the EOF first, second and third modes have contribution rates of $73.5 \%, 10.6 \%$ and $5.3 \%$, respectively. The spatial coefficient of the first mode $[\operatorname{EOF} 1(x, y)]$ shows synchronous temperature changes in the Tohoku District, while 
$\operatorname{EOF} 2(x, y)$ shows a seesaw pattern of temperature variation between the Pacific and Japan Sea sides. $\operatorname{EOF} 3(x, y)$ also have a seesaw pattern between the northern/southern areas of the Tohoku District.

2) The EOF time coefficients indicate that the air-temperature anomaly at the Hachinohe AMeDAS station, which has been used as a Yamase index, has high correlations with the decomposed EOF temperature variations, which are the first mode with correlation coefficient of 0.789 , and the first mode plus the second mode with correlation coefficient of 0.89 . It is found that the airtemperature anomaly at the Hachinohe station is related to two different patterns of the temperature variations in the Tohoku District.

3) It is demonstrated that the scatterometerderived surface winds over the oceans capture the Yamase winds well. The composite wind map, made through conditional sampling of days, with the Hachinohe $\Delta T<$ $-2^{\circ} \mathrm{C}$ shows that the northeasterly ocean winds blowing toward the Sanriku coast, a core of anti-cyclone in the eastern part of the Okhotsk Sea, and the northeasterly surface winds blowing along the Kuril Islands. When these winds approach the Hokkaido and Tohoku District in the Pacific Ocean, they separate into two flows around $40^{\circ} \mathrm{N}$ off Miyako.

4) The surface wind fields associated with the EOF first and second modes with negative temperature anomaly (i.e., cold phenomena) are different; the former indicates the northeasterly wind blowing toward the Sanriku coast and the latter that the northeasterly winds from the sea, south of the Kuril Islands change their direction around $145^{\circ} \mathrm{E}$, and the easterly winds blow toward the Sanriku coast.

\section{References}

Freilich, M., 1985: Science opportunities using the NASA scatterometer on N-ROSS, JPL publication, 84-57, 36pp.

Fujibe, F., 1995: Monthly mean temperature variation in summer at Northern Japan and its characteristics-Classification of cold summer based on principal component analysis-, Extended Abstract of Yamase Symposium-'93 Yamase and Its surroundings, Center for At- mospheric and Oceanic Studies, Faculty of Science, Tohoku Univ., 32-37 (in Japanese).

Heibonsha, 1987: Dictionary of Meteorology, Eds. Asai, T., E. Uchida, and T. Kawamura, Heibonsha, 528pp (in Japanese).

IFREMER/CERSAT, 2002: Mean Wind Fields (MWF product) User Manual Volume 2-QuikSCAT, C2-MUT-W-04-IF, Ver. 1, 47.

Kanno, H., 1993: Differences of temperature and humidity between Yamase and sea breeze and their seasonal variations at Hachinohe in Aomori Prefecture. Tenki, 40, 751-757 (in Japanese).

_ 1997: Classification of the Yamase (Cold Northeasterly Wind around Northeastern Japan) Based upon its Air-Mass Vertical Structures. J. Meteor. Soc. Japan, 75, 1053-1071.

Kawamura, H., 1995: Satellite remote-sensing for Yamase observations. Meteor. Res. Notes, 183, 153-179 (in Japanese).

- and P. Wu, 1998: Formation mechanism of Japan Sea Proper Water in the flux center off Vladivostok. J. Geophys. Res., 103, 2161121622 .

- 2003: Satellite remote sensing of the air-sea interaction, in "Ocean-Atmosphere Interactions" ed. Y. Toba, Ocean Sciences Research Vol. 3, Terra Science Pub., 239-298.

Kawamura, T., 1977: Areal distribution of surface winds in Japan. Technical Report of the Japan Meteorological Agency, 91, p76 (in Japanese).

Kodama, Y.-M., 1997: Airmass transformation of the Yamase Air-flow in the summer of 1993. J. Meteor. Soc. Japan, 75, 737-751.

Kon, Y., 1984: About "Yamase". The reports about the cold summer in the Tohoku District in the symposium of annual meeting in autumn. Tenki, 31, 165-170 (in Japanese).

Kondo, J., 1988: Volcanic eruptions, cool summer, and famines in the northeastern part of Japan. J. Climate, 1, 775-788.

Luis, A.J. and H. Kawamura, 2000: Wintertime Wind Forcing and Sea Surface Cooling Near the South India Tip Observed Using NSCAT and AVHRR. Remote Sens. Environ, 73, 55-64. - and - 2002: Mechanism for Sea Surface Temperature Cooling In the Gulf of Oman during Winter. Geophys. Res. Lett., 29, 16.

Ninomiya, K. and H. Mizuno, 1985a: Anomaly cold spell in summer over North eastern Japan caused by northeasterly wind from polar maritime airmass. Part 1. EOF analysis of temperature variation in relation to the large-scale situation causing the cold summer. J. Meteor. Soc. Japan, 63, 845-857. - and - 1985b: Anomaly cold spell in summer over North eastern Japan caused by 
northeasterly wind from polar maritime airmass. Part 2. Structure of the northeasterly flow from polar maritime airmass. J. Meteor. Soc. Japan, 63, 859-871.

Takai, H., H. Kawamura, and N. Ebuchi, 1996: A study on advection of the cool airmass of Ya- mase in 1993 summer. Kaiyo Monthly, 28, 1622 (in Japanese).

and - 2002: Cloud appearance rate in the Yamase days derived from the NOAA satellite and AMeDAS observations. Tenki, 49(12), 17-24 (in Japanese). 